\title{
Abrir caminos, emprender viajes: el currículum como experiencia de apertura
}

José Contreras Domingo

(Universitat de Barcelona)

mail: jcontrerasqub.edu

ORCID: https://orcid.org/0000-0001-9242-756X

\author{
Guiomar Manrique Ruiz \\ (Escola l'Univers, Barcelona) \\ mail: gmanriquaxtec.cat \\ ORCID: https://orcid.org/0000-0001-7316-8830
}

\section{RESUMEN}

En este artículo, mediante la indagación narrativa de historias vividas en una clase de educación primaria, se muestra una visión del currículum que lo entiende como un camino que va adquiriendo desarrollos singulares y cualidades propias en su transcurrir. Es el recorrido el que va componiendo el currículum, a partir de las historias vividas en la clase y de las historias de sus protagonistas, que se van transformando en el proceso. Un proceso de vidas e historias donde se inscriben los aprendizajes y saberes, de sí y de las cosas del mundo. El texto se estructura a partir de tres historias que permiten ver: a) la importancia de la invitación a recorrer el camino, de manera que este pueda ser habitado por sus protagonistas; b) cómo el currículum escolar entra en relación con el currículum de las vidas personales, y c) los potenciales conflictos entre las exigencias externas y las trayectorias personales.

Palabras Clave: Currículum; Creación curricular; Educación primaria; Indagación narrativa.

\section{Opening paths, embarking on new journeys: the curriculum as an experience of openness}

\section{ABSTRACT}

This article, through the narrative enquiry of stories experienced in a primary education class, shows a vision of the curriculum that understands it as a path that acquires unique developments and its own qualities in its course. It is the journey that makes up the curriculum, based on the stories experienced in the class and the stories of its protagonists, who are transformed in the process. A process of lives and stories in which the learning and knowledge of oneself and of the things of the world are inscribed. The text is structured on the basis of three stories that allow us to see: a) the importance of the invitation to walk the path, so that it can be indwelled by its protagonists; b) how the school curriculum enters into relation with the curriculum of personal lives, and c) the potential conflicts between external demands and personal trajectories

Keywords: Curriculum; Curriculum making; Primary education; Narrative inquiry.

ISSN: 0210-2773

DOI: https://doi.org/10.17811/rifie.50.3.2021.665-672 
Lo que el profesor hace no es anunciar una meta sino empezar un camino. (Larrosa, 2020, p.49).

\section{Comenzar un camino}

\section{En el taller de dibujo ${ }^{1}$}

Hace ya tiempo que tenía ganas de venir al taller de dibujo de los viernes por la tarde. Guio me había invitado a asistir, pero hasta hoy no me ha sido posible. Cuando llego, ya se encuentra en el aula el grupo de niñas y de niños que están haciendo este taller y nos saludamos. Son un total de 16, la mitad, de 5ㅁ, que es la clase a la que asisto regularmente, y la otra mitad, de 6⿳亠丷⿵冂丶, del grupo que tenía Guio el curso pasado y a quienes conozco de entonces, salvo a Sam y a Younis, que son nuevos este año.

Han creado un nuevo escenario en el aula: hay una mesa apoyada contra la pared a la que se subirá quien pose, y el grupo está sentado en el suelo, a su alrededor; todos van equipados con unos tableros con hojas A4. Se les ve tranquilos y parecen expectantes.

Para este grupo, esta es su cuarta sesión y, como hoy estoy yo, Guio recuerda con ellos que están haciendo apuntes gestuales del natural a partir de tres técnicas. Hoy probarán la tercera. Les propone dibujar a Sam, que ha salido a posar, a partir de múltiples trazos pequeños, casi de tanteo, para ir captando sus formas, su postura. Pero antes, para calmar la excitación y el nerviosismo del comienzo, les guía en unos breves ejercicios de relajación.

Les ha dado 5 minutos para esta primera prueba. Mientras dibujan sentados en el suelo, yo, de pie, me fijo en lo que hacen, y especialmente en su concentración, en su silencio, mientras los segundos pasan con calma. Al final, comentan cómo les ha ido; si les ha dado tiempo a terminar, si han podido incorporar detalles ("iMirad, Pau ha puesto algunas arrugas en la ropa de Sam!").

- ¿Cómo os habéis sentido? -les pregunta Guio-. Lo cual conduce a una breve conversación acerca de si estaban relajados o intranquilos, si les había dado tiempo a acabar...

Inician una nueva sesión. Ahora es Xavier quien posa. Mientras elige su postura, Guio les comunica:

-Esta vez tenéis que hacer un apunte en 10 minutos. Con detalles de la cara, de las manos...

Se producen diferentes reacciones:

- ¡Buf! ¡Cara y manos! ¡No podré!

- ¡Diez minutos! iQué palo!

$Y$ Guio les pregunta:

- ¿Qué emoción hay cuando decís que no podréis?

- Miedo.

- ¿De qué nos advierte el miedo?

- De que puede no salirnos bien.

- ¿Y pasa algo si no nos sale bien?

-... No...

- ¿De qué nos advierte el que nos da palo?

- De que me cansaré.

- Pues si nos cansamos, podemos parar.

Se han puesto a la tarea. Mi mirada va paseándose, prestando atención a sus cuerpos, sus posturas, sus manos, sus gestos de concentración. Me fijo también en Xavier, que posa con la mirada perdida, sin moverse, muy en su papel. No sé si le está resultando fácil, pero ahí está. Y pienso que eso es lo que están haciendo todos: estar en su papel, probar este ejercicio; un ejercicio que no es solo dibujar o posar, sino estar en él, probar este camino que Guio les ha ofrecido, para ver qué da de sí.

Cuando acaba el tiempo, se muestran unos a otros su obra y se hacen comentarios. Guio les vuelve a preguntar cómo se han sentido.
Laia contesta que en algún momento se ha agobiado porque no le salía.

- ¿Y qué has hecho? -le pregunta Guio.

- Pensar que no pasaba nada si me salía mal.

Han seguido haciendo pruebas. Al final, en una valoración de la jornada y de sus progresos han estado enseñándome y comparando los dibujos del primer día con los posteriores y hemos podido observar la evolución, en especial en la seguridad del trazo. Me llaman especialmente la atención los de Andrés, un niño con graves dificultades motoras y que no controla bien el trazo: su primer dibujo no consigue integrar un conjunto, pero los últimos sí.

Todo me va comunicando que, efectivamente, están probando un camino, están caminándolo, prestando atención al propio caminar y a sus frutos, como también a lo que les hace dudar. Pero la referencia de sus progresos no es externa. La referencia del camino no viene marcada por una meta a la que llegar, sino por la relación que van creando con los pasos que dan: su propia evolución, la de sus dibujos, la de su relación con sus frenos y tropiezos.

Llevo meses asistiendo a la clase de $5^{\circ}$ de Guio y es ahora, con este taller, como se me ha abierto a mí también un camino, un camino de comprensión de una forma de entender el sentido de la enseñanza y del currículum que se van componiendo en la clase. Un currículum y una enseñanza que puedo entender con más amplitud si los pienso como apertura de caminos de exploración. Caminos que se comienzan, y que están abiertos en sus posibilidades, y que solo cobran concreción en el transcurso del viaje, en sus significados y efectos concretos sobre la clase y sobre cada niña, cada niño. (Texto provisional de investigación de Pepe; febrero, 2019).

Comenzar un artículo con una historia es una forma de entender la investigación y su expresión desde la indagación narrativa (Clandinin, 2013). Porque son las historias las que van abriendo una ruta de exploración, para ir pensando con ellas los asuntos que se nos van revelando, y para ir tirando de algunos de los diferentes hilos que componen su trama, en relación con las cuestiones que queremos profundizar a través de ellas.

También, en este caso, es el comienzo de una escritura en colaboración entre un investigador y una maestra, un proceso abierto del que ir aprendiendo en el camino. Una colaboración que se inició con la petición de Pepe -profesor en la universidad de futuros docentes de educación primaria- a Guio -maestra en una escuela pública de Barcelona que cuenta con un proyecto singular- para asistir a sus clases y conversar sobre ellas, con el propósito de captar y aprender algo de lo que en la escuela se estaba viviendo y poderlo así llevar a la formación de maestras/ os. La investigación involucraba a la maestra y a su grupo de quinto curso. El foco estaba puesto especialmente en el currículum, entendido como aquel proceso vivo que va cobrando forma en el transcurso de las clases, y en cómo ese proceso se va constituyendo en las relaciones múltiples y variadas del aula (Rosiek y Clandinin, 2016; Huber et al., 2012). Como investigación viva, es también el comienzo de un camino; su foco es un faro de referencia, pero solo es el caminar el que va mostrando sentidos y posibilidades. Es en la vida que se da y en las vidas que conviven donde buscábamos entender de qué forma se iba componiendo el currículum (Clandinin, 2020). Y es así como fuimos captando y componiendo historias relevantes que nos ayudaban a pensar el currículum de la clase y cómo este se sostenía en el entramado de historias que se iban sucediendo y que cada cual iba viviendo desde sus propias historias.

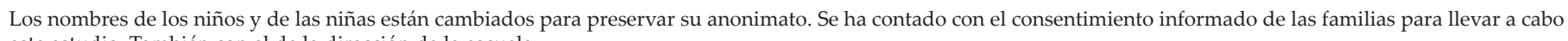
este estudio. También con el de la dirección de la escuela. 


\section{El currículum como invitación}

Pero volvamos al taller de dibujo, porque en su historia se entrelaza la de la escuela y su proyecto educativo, con la de Guio. El taller nació en el seno de una propuesta más amplia, diseñada por el equipo docente, de tres talleres simultáneos en los que se mezclan niñas y niños de $5^{\circ}$ y $6^{\circ}$ : Inspir-Arte, Recicl-Arte y Dibuj-Arte. El de dibujo lo concibió Guio a partir de su experiencia de los apuntes gestuales del natural, un taller que había vivido en su período de formación como maestra. Esta experiencia germinal fue cobrando forma a principios de curso, haciendo pruebas en ratos libres en la clase (con el maniquí de dibujo, o pidiéndole a algún niño que posara), para ver lo que requería, imaginar lo que podría suceder en su desarrollo y pensar cómo plantearlo a la clase. Para Guio era fundamental probar el taller con ella misma, porque como habíamos compartido en más de una ocasión en nuestras conversaciones, "antes de proponerles una investigación, tienes que hacerla tú. Si no, vas al resultado, no al proceso. Y el acompañamiento es patético" (Conversación, marzo 2018).

Este acompañamiento no se refiere solo al apoyo en los procesos de comprensión y realización de la actividad. En su forma de entender su trabajo como maestra es también fundamental el acompañamiento emocional, basado en toda su formación y experiencia de años en educación socioemocional (Bueno, 2017; Carpena, 2012; Vallvé y Manrique, 2021). Cuando llegó a L'Univers, la escuela en la que trabaja en la actualidad ${ }^{2}$, pudo integrar esta perspectiva de atención a los procesos emocionales en un proyecto escolar que pone el centro en el proceso que hace el alumnado, a partir de propuestas y actividades que permitan a los niños explorar, preguntarse, probar... Según lo expresaba en una de nuestras conversaciones:

En esta escuela, las maestras me han enseñado el colofón: que no solo es la educación emocional, sino que es una escuela donde yo no soy el centro. Eso lo estoy aprendiendo todavía. Yo antes conducía la clase todo el tiempo. Yo tenía la información, la transmitía, hablaba y decidía todo. Y no tenía tiempo de acompañarlos. Cuando aprendes a generar actividades en las que ellos sean los que hagan el proceso, tienes tiempo para poderlos acompañar. Es él el que hace, no yo. Y tienes tiempo para desarrollar ese vínculo, que es el que hará que las cosas tiren para arriba. Demostrarle a cada uno que es capaz... mientras que los docentes que tuve en mi infancia y adolescencia en muchas ocasiones me hicieron creer que no servía. (Conversación, marzo 2018).

La mayor parte de las actividades que se realizan en esta escuela tienen este aire común de proponer algo para hacer que resulte sugerente, algo que actúa como una invitación a probar cosas nuevas. Ya se trate del tiempo dedicado a introducirse en nuevos dominios de la matemática, a partir de enfrentar situaciones que necesitan comprender o resolver. $\mathrm{O}$ en variadas propuestas de escritura, en las que experimentan y prueban a hacer algo propio a partir de alguna referencia inicial (y la gramática va apareciendo para mejorar y potenciar sus recursos para escribir). O también, el modo en que están concebidos los Espacios (ambientes de aprendizaje autónomo y cooperativo a partir de propuestas de investigación, estudio o acción, contenidas en lo que llaman "cajas de aprendizaje" en las que los alumnos encuentran todo lo necesario para llevar a cabo la propuesta, incluida su autoevaluación). O las conferencias que preparan. $\mathrm{O}$ los proyectos que realizan. Siempre tienen una misma base: una invitación a comenzar un camino. Algunos están más definidos, con referencias a las que ir atendiendo, y otros menos, a la espera de las decisiones que irán tomando en el proceso. Pero en todos ellos, lo que cuenta es el propio camino; la experiencia educativa y de aprendizajes que se va viviendo y el acompañamiento que se va cuidando.

En los caminos que cada criatura está recorriendo en el taller de dibujo se valen de técnicas (las de los apuntes gestuales), de prácticas (el ejercitarse en sí, para probar y probarse en eso de dibujar del natural) y de la seguridad que Guio intenta que vayan desarrollando como cuidado de sí, como fortaleza, para caminar. Porque aprender a identificar y gestionar las emociones ayuda a caminar con más seguridad, con más plenitud. En esta manera de vivir el currículum que se va gestando y componiendo en la clase, no cuenta tanto el dispositivo (entendido como conjunto de contenidos, actividades y resultados previstos) como el sentido más etimológico del término: el recorrido que se va realizando. Por eso, el auténtico currículum solo se entiende en el recorrido y en las historias de quienes lo viven (Clandinin, 2020).

El camino que se propone y que se invita a comenzar se ofrece como una vía de experiencia de alguna faceta del mundo, del saber o de la cultura que se propone para ser explorada (Biesta, 2017). En el taller de dibujo, las técnicas de apunte gestual son formas de mirar, de captar y de expresar el cuerpo humano. Lo que cuenta es la atención al cuerpo, una atención que se presta con la vista y con la mano que dibuja. En esta propuesta curricular se ha creado un camino en el que adentrarse. Pero, en ese recorrido, lo que se crea es la atención (Larrosa, 2019).

Reconocer en esta historia de la clase de Guio el sentido del currículum que se va creando lleva a Pepe a pensar en sus clases y en cómo hacer llegar este sentido a sus estudiantes de magisterio. Cómo comunicar, con esta y otras historias, que la cuestión fundamental no es el deslumbramiento de la innovación, ni la espectacularidad de la invención. Que lo fundamental es el cuidado en la creación de un proceso abierto que invita, que acoge y que atiende al proceso singular por el que cada niña, cada niño vive como algo genuino un quehacer que le requiere atención y prueba, sin más interés que el hacer algo tan bien como pueda, para abrirse a nuevas percepciones de lo que le rodea. (Biesta, 2017). Y cómo comunicarlo a sus estudiantes mostrando, también, su complejidad y sus tensiones. Porque las metas, inevitablemente, aparecen en el horizonte de las exigencias de la escuela y de las exigencias $a$ la escuela.

\section{Recorrer un camino de indagación narrativa}

Indagar a través de historias vividas en el proceso nos marca el camino de nuestra investigación. La indagación narrativa tiene como propósito el estudio de la experiencia entendida narrativamente (Clandinin, 2013; Clandinin y Connelly, 2000). La forma narrativa de la experiencia es a la vez fenómeno (lo que se estudia) y método (el modo de hacerlo). Es fenómeno en tanto que la experiencia se expresa narrando historias. Pero como método, la indagación narrativa atiende al devenir de la experiencia y de las historias con las que damos cuenta de ellas. Porque la experiencia no es estática, ni tampoco lo son las historias que contamos. La indagación narrativa explora y promueve esta dimensión cambiante de las experiencias y de las vidas de las personas, así como de las historias que contamos para expresar y dar sentido a las vidas y a lo vivido. $Y$ el modo en que lo hace es pensado narrativamente: componiendo historias que emergen con el proceso de investigación, reconociendo y profundizando 
en sus dimensiones narrativas, para continuar componiendo nuevas versiones de las historias que atiendan a la complejidad de las múltiples capas presentes en las historias que vivimos y contamos, imaginando nuevas posibilidades para ellas, hasta "escribir textos de investigación en medio de la incertidumbre" (Clandinin y Connelly, 2000, p. 144).

Al comprender la experiencia en su devenir, la indagación narrativa es consciente de que las historias vienen de antes y de que continuarán después de que finalice la investigación. Por eso se propone preguntarse por los sentidos de los acontecimientos y sugerir nuevas posibilidades en un ejercicio de apertura de la imaginación (Greene, 2005). Con un fundamento ontoepistemológico transaccional (basado en Dewey) y relacional (Clandinin y Rosiek, 2007), la indagación narrativa no busca la representación de la realidad independientemente de quien investiga, sino generar nuevas relaciones con quienes participan en la investigación a partir de las cuales componer nuevas historias que puedan ir evolucionando para abrir la posibilidad de nuevas experiencias (Clandinin, 2013).

Este estudio es parte de una investigación más amplia que tenía por propósito profundizar en los procesos de creación curricular en las escuelas y el modo de hacerlos presentes en la formación inicial del profesorado ${ }^{3}$. La investigación estaba concebida de un modo abierto en cuanto a los significados de la creación, a la espera de ir comprendiendo sus sentidos en el suceder de los procesos de clase y de las historias de sus participantes. Al acompañar a las diferentes clases, junto con sus maestras, lo que nos guiaba era comprender los transcursos reales de los procesos de enseñanza y comprenderlos en el contexto de las historias colectivas e individuales. Lo que buscábamos como equipo de investigación era una comprensión narrativa del currículum que nos nutriera de historias con las que pensar y dar a pensar la complejidad currícular a los estudiantes de magisterio; pero también que esta comprensión narrativa nos diera la oportunidad de repensar las prácticas de formación acogiendo en ellas los procesos de creación.

Convivir con la clase de $5^{\circ}$ por parte de Pepe, recogiendo y elaborando diferentes registros de campo, junto con las conversaciones con Guio, en las que ambos íbamos explorando las distintas capas presentes en las historias de la clase, dieron lugar a la elaboración de unos primeros textos narrativos, elaborados por Pepe, que fueron evolucionando en posteriores versiones. De este modo podíamos percibir poco a poco la forma en que las relaciones y la gestación del currículum en el aula se iban entramando.

Escribir conjuntamente el artículo nos ha permitido volver sobre las historias y seguir profundizando en sus múltiples significados, pudiendo pensarlas y pensarnos de nuevo en relación con lo vivido y en relación con nuestras propias historias también presentes: la de Guio como maestra interesada en la formación de educadores; la de Pepe como formador interesado en la educación escolar. Hemos seleccionado historias a partir de las cuales profundizar en el sentido dinámico y singular en que el currículum se va configurando en el vivir de la clase, de las niñas y de los niños y de su maestra.

\section{Emprender el viaje: entre el currículum de la clase y el currícu- lum personal}

La invitación a recorrer un camino se le hace a la clase en su conjunto, pero cada estudiante emprende a la vez un viaje singular. Un viaje que tiene que ver con las historias particulares que vive, y desde las que se vive. La historia que sigue nos permite atender a esta trama entrelazada entre historias personales y colectivas con las que se van componiendo los múltiples currículums que existen en una clase.

Hace dos semanas que, en la hora dedicada a la escritura creativa, los martes por la tarde, están trabajando sobre el "binomio fantástico". Adaptando la idea de Rodari (1983), están escribiendo un relato a partir de una palabra que inventan juntando otras dos. Prácticamente tienen acabados sus textos, así que la consigna de hoy es que los finalicen, los pasen a limpio y los revisen para leerlos en voz alta al grupo. El ambiente oscila entre la celeridad por acabar la tarea a tiempo, la calma y concentración necesaria para hacer una buena copia definitiva y los nervios de la preparación para la lectura a la clase.

Mientras trabajan, yo deambulo por el aula, echando un vistazo a lo que van haciendo y me mantengo disponible por si necesitan algo. Rocío, con la espalda bien erguida, está concentrada en la reescritura de su texto, corrigiendo las faltas que le ha señalado Guio de la versión anterior. No parece perturbarle el ambiente a su alrededor. Me aproximo para ver qué hace, pero ella, discretamente, tapa su hoja de mi vista.

Llega el momento de la lectura. Se colocan en círculo, sentados en el suelo. Cuando le toca el turno, Rocío nos lee un relato de una gimnasta que se lesiona antes de un importante campeonato y el médico le dice que tendrá que abandonar la gimnasia. Pero ella no se rindió y consiguió recuperarse a tiempo de participar en el campeonato. No ganó, pero -finaliza su relato- "le sirvió para esforzarse más en las cosas".

Al acabar, Guio pregunta al grupo "¿Qué nos enseña este cuento?" A lo que respondieron "Que hay que esforzarse".

El cuento de Rocío, como la mayoría de los que han escrito el resto de la clase, tiene un contenido moral, con una moraleja que todos han captado. Pero ya desde la semana anterior, conforme íbamos viendo los relatos que estaban componiendo, pudimos advertir que eran además historias en las que se proyectaban. En cada relato, cada unalo estaba contando una historia en la que se reflejaban sus preocupaciones, sus actitudes, sus esperanzas. Por eso, había decidido Guio preguntarles, al acabar cada lectura, qué nos enseñaban esos cuentos. Y ha aprovechado el momento para ayudarles a hacer más explícitos aún esos mensajes cuando no estaban suficientemente claros: "¿A quién no le ha pasado algo así?". "Quiere decir que no tenéis que perder la esperanza". "Que, aunque te dé miedo, tienes que ser valiente". "El valiente no es el que no tiene miedo, sino aquel que a pesar del miedo sigue adelante con sus propósitos". "Quiere decir también que estáis creciendo".

En la conversación después de la clase, aún impresionados por sus relatos y lo que estos reflejaban, Guio me cuenta que Rocío practica la gimnasia rítmica, pero que su escrito probablemente revela una lucha que no se reduce a la de esa actividad. ¿De qué nos está hablando Rocío? Y nos preguntábamos si la historia que cuenta no será una historia que ella se cuenta a sí misma: una historia en la que una lesión es el reflejo de sus adversidades y en la que elabora su deseo de superarlas. Una historia que ya viene de lejos y de la que Guio está pendiente desde que empezó el curso. (Texto provisional de investigación de Pepe; noviembre, 2018).

El camino abierto con el "binomio fantástico" le permitió a Rocío, como a otros niños, contar simbólicamente su historia, y a la vez, imaginar nuevos desarrollos más esperanzadores. Hizo

“Relaciones educativas y creación del currículum: entre la experiencia escolar y la formación inicial del profesorado. Indagaciones narrativas” (EDU2016-77576-P) (AEI/ FEDER, UE). 
posible que una tarea escolar de escritura se convirtiera en un trabajo personal, en un trabajo de sí. Favoreció que el currículum de la clase se transformara en parte de su currículum personal; que el currículum escolar se convirtiera en una palanca para su proceso personal de formación.

El viaje que hace conjuntamente la clase está mediado por la percepción que la maestra tiene de estas diferentes historias particulares. Desde el comienzo del curso, Guio comparte con Pepe diferentes historias que a ella le llegan de los niños de 5ํ. Algunas de ellas las tiene presentes como historias que es necesario que puedan evolucionar para que así puedan aflojarse algunos frenos interiores, o destensarse algunos conflictos de relación, o para que pueda aparecer la posibilidad de nuevas historias, de nuevos procesos de crecimiento. Como también, el proceso del curso le permitió modificar algunas historias que le habían contado o que ella misma se había contado acerca de algunos niños. Porque, como aquel día le dijo Guio a Pepe, y le repetiría en más de una ocasión, "lo importante es saber qué hay que cuidar en cada uno". En la historia que ella recibía sobre Rocío a principios de curso estaban presentes algunos desencuentros con otras niñas de la clase que hacían que no acabara de encontrar su lugar en el grupo. Es una niña con criterios firmes -que muestra con claridad en su personal manera de vestir- pero también reservada y no se muestra segura en la clase, lo cual entorpece su proceso de aprendizaje. Una historia, como nos muestra en su cuento, que parece que está empezando a cambiar.

Al inicio del curso, la maestra contó a la clase que este año no harían proyecto, sino que prepararían conferencias individuales, para así poder estudiar y exponer a la clase aquellos temas que les interesen individualmente. Aunque esta es una decisión de escuela, sin embargo, en clase defendieron que, además, querían seguir haciendo juntos algún proyecto y acordaron hacerlo a partir de un deseo compartido: querían cocinar. Pero pronto se reveló que cocinar para la clase requería tener en cuenta algunas precauciones:

Guio les ha advertido que cocinar en la escuela requiere cumplir con toda una serie de normas sanitarias que tendrán que preguntar. Y también, que deberán tener en cuenta las intolerancias alimentarias que hay en la clase, como la celiaquía de Rocío. Muchos no sabian de qué se trataba y Guio les ha explicado qué es el gluten, en qué consiste esta enfermedad y cuántas precauciones es necesario tener a la hora de cocinar para evitar la contaminación con gluten durante el proceso. Me ha sorprendido el conocimiento que tiene Guio del tema. Pero más aún me ha sorprendido el interés y la atención con la que toda la clase ha seguido la explicación. Y he podido apreciar cómo un tema que parece que solo afecta a una niña se ha convertido en la apertura a la comprensión, para toda la clase, de un asunto complejo y cada vez más presente en nuestra sociedad. (Texto de campo de Pepe, septiembre 2018).

Más tarde, Guio revelaría a Pepe que tiene amigas celíacas y que de aquí venía su conocimiento sobre el tema. Pero que, por encima de su conocimiento, era su historia personal en relación con sus amigas lo que le permitía a ella "hablar desde su verdad, desde un saber vivo en ella, y no desde el conocimiento". Y que de aquí venía el interés y la atención que manifestó la clase a sus explicaciones.

Desde que empieza el proyecto de cocina, Guio percibe que se abre un camino para transitar algunas de las dificultades de Rocío y para "empoderarla". Su familiaridad con las intolerancias alimentarias la lleva a que esta preocupación esté presente en todo el proyecto, de tal manera que la necesidad de Rocío (y la de otros niños con intolerancias a la lactosa y a los caca- huetes), fuera la de todos. El reto de cocinar repostería se convirtió en hacerlo sin ciertos ingredientes, y con especial cuidado en los procesos. El conocimiento de la celiaquía, de sus causas y de las precauciones necesarias normalizaba la presencia de las intolerancias y a la vez permitía a Rocío ser de algún modo la protagonista sin ser "la rara". Y para toda la clase, significaba la oportunidad de adquirir un compromiso con lo que estaban explorando. Porque el propósito de la enseñanza no es "proporcionar a los niños el conocimiento de un mundo ya determinado"; no se reduce a asegurar su comprensión, sino a "proporcionar a los niños la oportunidad de comprometerse con él para responder responsablemente... Los niños deben tener la oportunidad de responder al contenido del currículum, hacer elecciones, tomar postura y ser escuchados". (Osberg y Biesta, 2007, pp. 47-49).

El cuento de Rocío sobre la gimnasta tuvo su continuidad en la conferencia que dio a la clase, ya avanzado el curso, sobre mujeres deportistas en la historia. Ya no es una ficción simbólica, sino historias de mujeres deportistas que han vencido resistencias sociales y culturales para poder dedicarse a lo que desean en la vida, mujeres que abrieron camino a otras mujeres y sobre las que Rocío ha investigado. Lo que ahora ella ofrece a la clase son historias sociales que pueden servir de referencia a otras niñas; y quizás también, historias que permiten mostrar que la singularidad y la determinación pueden abrir caminos para sí y para otras y otros.

No sabemos qué historia escribiría ahora Rocío acerca de una gimnasta. Ni siquiera si sigue necesitando contar relatos de gimnastas para contarse a sí misma. Pero el currículum personal que va componiendo, entre sus historias, sus intereses y el acompañamiento que tiene de su maestra y de la escuela, la conducen a un modo de caminar en el mundo, abriéndose a nuevas experiencias.

“El currículum... implica asistir a los alumnos a adquirir nuevos hábitos de ser y estar en el mundo -no solo lo que de un modo restringido llamamos conocimiento, sino también temperamento, disposición, apreciación estética, entusiasmo por temas específicos, inteligencia emocional, ética, compasión, etc." (Rosiek y Clandinin, 2016, p. 297).

El currículum tiene que ver con las historias personales de relación con el mundo y cómo estas historias se van transformando en el proceso curricular vivido en la escuela. Tiene que ver con el acceso a un saber que no se reduce a posesión de información, sino que se vive como un conocimiento encarnado (como el que le permite a Guio hablar desde su verdad, desde un saber vivo en ella). El acceso a nuevos saberes está mediado por, y mediando nuestro ser en el mundo, nuestra forma de vivirnos y entendernos. Un ser, una forma de vivirnos y entendernos, que se va configurando y evolucionando en las historias que vivimos, historias que son también de conocimiento, de exploración, de búsqueda de comprensiones que nos den sentido a nuestra vida en movimiento.

En la invitación a recorrer caminos y a habitarlos que configura el currículum de la clase de $5^{\mathbf{o}}$ en esta escuela, algunos de ellos están suficientemente dibujados; pero otros son, más bien, invitaciones a crear sus propios caminos. Porque no siempre sabemos cuáles puede habitar un niño, qué necesita experimentar y probar hasta ir consiguiendo la suficiente seguridad y confianza como para abrirse a nuevas exploraciones, nuevos caminos. La invitación es a abrirse al mundo (Biesta, 2017). Pero para abrirse al mundo hay que abrirse a sí, para poder mirar con apertura al mundo; y apertura, en Rocío, era también hacerlo con flexibilidad, con afán de superarse, para sentirse capaz... y hacerlo con realismo, esto es, aunque no gane la competición. 


\section{Cuando el camino parece que se estrecha: la tensión con las} metas

Desde que ha empezado el curso, Guio me ha manifestado en varias ocasiones su preocupación porque ve en muchos niños y niñas un nivel más bajo del que les correspondería para $5^{0}$ y teme que el próximo año sean pocos los que puedan superar las pruebas externas de competencias básicas. En la primera conversación pausada que hemos conseguido tener, tres semanas después del inicio del curso, este asunto ha estado presente: "Tal y como los veo ahora, ¿quién superará esas pruebas?... Estos niños se han educado en los recortes [por la crisis económica], con servicios educativos desbordados y sin poder detectar a tiempo ni dar apoyo a sus necesidades". $Y$ a continuación, coge la lista de la clase y me va diciendo, uno por uno, si cree que pasarán o no. "Me angustia. Mi responsabilidad es que cuando acaben primaria sean lo más autónomos y competentes posibles para secundaria".

Antes del verano ya me había advertido que tendría un grupo muy dispar en el que había bastantes niños con dificultades de todo tipo y que tendría que ver cómo podría ir gestionando todos los asuntos a los que se enfrentaría. Pero ahora me habla desde una preocupación presente y muy centrada en lo que se supone que tendrían que dominar como saberes y capacidades, lo que esto le exige ("no me sirven muchas de las actividades que ya tenía del año pasado; tendré que ir viendo") y lo que teme como fracaso de muchos en esas pruebas. (Texto provisional de investigación de Pepe; octubre, 2018).

Las pruebas de competencias básicas que realiza obligatoriamente el alumnado en $6^{\circ}$ no tienen efectos ni en las calificaciones ni en su paso a secundaria (Generalitat de Catalunya, 2016). Pero Guio habla en estos momentos desde su preocupación acerca de si sus alumnos estarán preparados para seguir con normalidad la educación secundaria. Una preocupación que se expresa con sus dudas acerca del nivel que tienen y de si superarán la prueba. Y que revela el conflicto potencial de la enseñanza reglada para muchos docentes: entre atender a las necesidades del proceso de formación adecuado para cada niña o niño, o atender a las exigencias externas, en este caso, el dominio de conocimientos que determina una prueba y prepararlos para estudios posteriores. Una tensión entre el currículum real que van realizando y las presiones del currículum que marca la evaluación externa.

En las historias vividas a lo largo del curso, y en las conversaciones que hemos ido manteniendo, este conflicto ha ido expresándose, a veces de modo implícito, a veces de forma explícita. Desde la perspectiva que defiende esta escuela, y que Guio comparte, lo que cuenta es que niñas y niños vivan el proceso y no que estén pendientes de los resultados. No hacen exámenes, ni les ponen notas por sus tareas. Las valoraciones que reciben son siempre con respecto a la cualidad de lo que hacen y a las finalidades internas de las tareas; son valoraciones sin cuantificación, reflexivas; y a menudo auto-reflexivas de los niños sobre su proceso y sus avances en lo que están haciendo o en los retos que tienen. En este contexto, el currículum oficial les sirve como un indicador de referencia. Pero desde las pruebas externas de competencias, parece que esos indicadores se convierten en pruebas inapelables de los logros.

¿Cuál es la diferencia entre preocuparse por cómo estos niños avanzan, aprenden, en qué tienen dificultades, qué necesitan, qué les puede ir bien, por un lado, y por otro, la preocupación por un referente externo respecto a resultados que tienen que alcanzar y demostrar con un tipo de pruebas iguales para todos, independientemente de las necesidades particulares de aprendizaje?
¿Cuándo las exigencias externas actúan como referencias para orientar el camino y cuándo se convierten en amenazas, que impiden guiarse por los criterios internos del proceso que se vive? Una pregunta para hacernos como docentes. Pero también una pregunta con la que atender a los procesos de nuestros alumnos.

Nada más empezar la mañana, Guio les cuenta que hoy harán una prueba "para ver lo que sabéis de Mates aplicadas a la vida".

- En la vida hay que hacer pruebas: el carné de conducir, para entrar a la universidad, para oficios, las pruebas que tendréis en $6^{0}$... Ahora tenéis que trabajar solos; no se puede preguntar. ¿Para qué me servirán? Para ver en un papel lo que sabéis. Y para que veáis como os enfrentáis a una prueba. Cómo gestionáis vuestras emociones.

Y tras hablar un rato sobre las emociones que pueden surgirles y cómo manejarlas, les dirige una relajación para calmarlos.

Les reparte dos tipos de hojas con pruebas diferentes; y a Andrés y a Juan (que tienen un Plan individualizado) les proporciona otro tipo de ejercicios.

Están en silencio y va pasando el tiempo. Conforme terminan con la primera hoja, Guio les da una nueva. Cada uno va avanzando a su ritmo. Veo que Greta no ha pasado de la primera hoja; escribe titubeando, pero borra a menudo y vuelve a escribir. Hasta que rompe a llorar. Guio la tranquiliza: "Dudas tanto de ti que piensas que sabes menos Mates de las que sabes. Borras sin saber por qué". (Texto de campo de Pepe, noviembre 2018).

¿Cómo nos relacionamos con las exigencias externas? ¿Tanto nosotros como los niños?

Ahora, en la distancia con lo sucedido a lo largo de ese curso, Guio le cuenta a Pepe que era su miedo lo que estaba actuando. Ante la posibilidad de tener al mismo grupo el curso siguiente sería la primera vez que tendría un $6^{\circ}$ que pasaría esas pruebas. $\mathrm{Y}$ estaba presente el temor a que los resultados de los niños se tradujeran en un juicio implícito a su actuación profesional. Pero precisamente por eso, piensa que es fundamental no transmitir ese miedo. Parte del camino como docente es saber afrontar estas dificultades del modo menos lesivo para los niños.

Al final, debido al estado de alarma por la pandemia, se suspendieron las pruebas de competencias básicas. Aunque en realidad, antes del confinamiento, la mayoría de estudiantes estaba ya en disposición de pasar las pruebas externas; la evolución durante el curso había sido grande, tanto en los aprendizajes como en lo madurativo, hecho que sorprendió gratamente a Guio. Para ella, un estímulo externo como son esas pruebas puede ayudarles a darse cuenta de que es necesario "ponerse las pilas", que hay que saber afrontar un examen, que a veces hay objetivos que nos vienen dados desde el exterior y hay que saber afrontarlos. Pero claro, los objetivos externos son estímulos externos, y no amenazas, si hay un ambiente que acoge y un proceso que ayuda a situarlos. Y si pueden ser vividos como una referencia de camino y no como una barrera amenazante para algunos. Saber cuándo es una cosa $u$ otra hay que poderlo leer en las historias particulares de cada curso, de cada estudiante, de cada docente. Porque lo importante es no perder las ganas de aprender, de seguir indagando en los propios procesos de aprendizaje... Y las pruebas externas, iguales para todos, pueden suponer para algunos una experiencia frustrante e injusta, algo muy distinto a aprender desde un punto de partida adecuado a las necesidades de cada uno.

El currículum se va componiendo como producto de muchas influencias y de muchas historias. $\mathrm{Y}$ entre ellas se encuentran también las que vienen condicionadas por las exigencias exter- 
nas. Convertir relatos enfrentados, como los que inicialmente representan las metas internas frente a las externas, en relatos complementarios, es un modo de abrir la posibilidad a lecturas más complejas y ricas de la realidad y a caminos curriculares con más tramas para recorrer (Olson, 2000). Pero también es cierto que, para algunos, esa confrontación de currículums entre el exigido y el vivido no es fácil ni justa (Biesta, 2019).

\section{Un camino que no acaba}

Las metas señalan un final. Los cursos acaban. Pero las historias quedan abiertas, señalando posibilidades, imaginando otros desarrollos, otras historias. Pensar el currículum como un camino que se inicia es un modo de abrir la imaginación pedagógica hacia las historias que están por suceder o por recomponerse. Historias vividas colectivamente en la clase, e historias personales que se van reconfigurando en el transcurrir de esa vida compartida. Como es también imaginar el currículum como un proceso vivo; un currículum que no es concebido como planes cerrados y resultados anticipados, sino como caminos y recorridos frágiles, inestables, en los que algo pueda suceder, algo pueda sucedernos.

En las historias que aquí hemos visitado hemos podido reconocer la importancia de los inicios de algunos de estos recorridos, en lo que tienen de apertura. Hemos podido atender a los procesos reales que se ponen en marcha y que les dan a los recorridos su auténtico valor, cuando las propuestas pueden ser habitadas por sus protagonistas desde sus propias historias. Nos hemos acercado a historias que nos ayudan a entender que el currículum escolar también se compone en el plano del currículum de las vidas singulares. $Y$ hemos reflexionado sobre las ambigüedades y los conflictos que pueden ocasionar las expectativas y las exigencias externas en las trayectorias personales.

Los niños y las niñas no solo realizan tareas escolares; también están componiendo sus vidas. Y nos podemos preguntar cómo captamos y acompañamos esos procesos más amplios que suceden junto a la apertura a los saberes y al mundo. Y cómo los docentes componemos también nuestros currículums. El de Guio, que se va haciendo maestra con lo que va viviendo en su clase. El de Pepe, que se va haciendo maestro al compartir por un tiempo con ella y con su clase estas historias; y que, mientras, imagina cómo puede enriquecer sus clases y cómo pueden enriquecerse, con estas historias, sus estudiantes, docentes en formación. Y como estos pueden abrirse a vivir con sus futuros alumnos nuevas historias con las que ir creando el currículum de la clase y de sus vidas. Porque como expresaba Guio en una de nuestras últimas conversaciones, "al final es un camino que hacemos todos. Yo recorro mi propio camino y ellos los suyos" (Conversación, marzo 2021).

\section{Referencias bibliográficas}

Biesta, G. J. J. (2017). The rediscovery of teaching. Routledge. https:// doi.org/10.4324/9781315617497

Biesta, G. (2019). What kind of society does the school need? Redefining the democratic work of education in impatient times. Studies in philosophy of education, 38(6), 657-668. http:// dx.doi.org/10.1007/s11217-019-09675-y

Bueno, D. (2017). Neurociencia para educadores. Octaedro.

Carpena, A. (2012). Com ets sents? Educació socioemocional dels 5 als 12 anys. Eumo

Clandinin, D. J. (2013). Engaging in narrative inquiry. Routledge. https://doi.org/10.4324/9781315429618

Clandinin, D. J. (2020). Narrative understandings of lives in schools. En D. J. Clandinin Journeys in narrative inquiry. The selected works of D. Jean Clandinin (pp. 149-159). Routledge. https://doi.org/10.4324/9780429273896

Clandinin, D. J., y Connelly, F.M. (2000). Narrative inquiry. Jossey-Bass.

Clandinin, D. J., y Rosiek, J. (2007). Mapping a Landscape of narrative inquiry. En Clandinin, D. J. (ed.) Handbook of narrative inquiry (pp. 35-75). Sage. https://doi. org/10.4324/9780429273896-15

Huber, J., Murphy, M. S., y Clandinin, D. J. (Eds.) (2012). Places of curriculum making: Narrative inquiries into children lives in motion. Emerald. https://doi.org/10.1108/s1479-3687(2011)14

Generalitat de Catalunya (2016). Orden ENS/164/2016, de 14 de juny, per la qual es determinen el procediment i els documents i requisits formals del procés d'avaluació en l'educació primària. Diari oficial de la Generalitat de Catalunya, № 7148, del 23 de junio de 2016. Catalunya, España.

Greene, M. (2005). Liberar la imaginación. Graó.

Larrosa, J. (2019). Esperando no se sabe qué. Sobre el oficio de profesor. Candaya.

Larrosa, J. (2020). El profesor artesano. Materiales para conversar sobre el oficio. Laertes.

Olson, M. (2000). Curriculum as multistoried process. Canadian journal of education, 25(3), 169-187. Disponible en https://journals.sfu.ca/cje/index.php/cje-rce/article/view/2781

Osberg, D., y Biesta, G. J. J. (2007). Beyond presence: epistemological and pedagogical implications of strong emergence. Interchange, 38(1), 31-51. https://doi.org/10.1007/s10780-0079014-3

Rodari, G. (1983). Gramática de la fantasía. Argos Vergara.

Rosiek, J., y Clandinin, D.J. (2016). Curriculum and teacher development. En D. Wyse, L. Hayward y J. Pandya (Eds.), The SAGE handbook of curriculum, pedagogy and assessment (pp. 293-308). Sage. https://doi.org/10.4135/9781473921405.n19

Vallvé, A., y Manrique, G. (11 de marzo de 2021). Educació emocional amb infants i joves. Claus per acompanyar la resolució de conflictes. Som I Salut Mental 360. https://www.som360. org/ca/blog/educacio-emocional-infants-joves 
